\title{
HUBUNGAN POLA ASUH DENGAN POLA PERKEMBANGAN SEKSUAL SEKUNDER PADA SISWA SMP
}

\author{
Uci Mayang Sari ${ }^{1}$ Suci Musvita Ayu ${ }^{1}$
}

${ }^{1}$ Universitas Ahmad Dahlan Yogyakarta

\begin{abstract}
Background: Adolescence is a transition period from childhood to adulthood, both physically and psychologically. Parents are generally considered as primary teachers for their children, therefore parents play important roles in children development. Parenting style is one of the factors associated with the pattern of secondary sexual development.

Objective: This study aimed to examine the relationship between parenting style and the pattern of secondary sexual development in junior high school students.

Methods: This research was an observational analytic study, using cross sectional approach. The study population was all male students at SMP 1 Berbah Yogyakarta (188 students). Samples were selected using purposive sampling, involving 143 respondents. Data were analyzed with Chi square test.

Result: There was a correlation between parenting style and the pattern of secondary sexual development $(p=0.000<0.05)$, with PR value of $4,975, \mathrm{Cl} 95 \%$ of $1,831-13,516$.

Conclusion: There was a relationship between parenting style and the pattern of secondary sexual development in junior high school students.

Keywords: Adolescence, Parenting, Patterns of Sexual Secondary Students
\end{abstract}

\section{PENDAHULUAN}

Masa remaja adalah masa peralihan dari anak-anak ke dewasa, bukan hanya dalam artian psikologis tetapi juga fisik. Selama masa remaja seluruh tubuh mengalami perubahan, baik dibagian luar maupun dibagian dalam tubuh, baik dalam struktur tubuh maupun fungsinya. Remaja pada tingkat Sekolah Menengah Pertama berada pada tingkat perkembangan yang disebut "Masa Remaja atau Pubertas". Remaja yang sedang mengalami proses transisi atau pubertas memiliki ciri-ciri dalam pertumbuhan fisik, psikis dan sosialnya ${ }^{(1)}$. Pada umumnya remaja mengalami berbagai kesulitan dan masalah dalam melakukan penyesuaian diri terhadap dirinya dan lingkungan pada masa pubertas. Perubahanperubahan fisik menyebabkan kecanggungan bagi remaja karena ia harus menyesuaikan diri dengan perubahanperubahan yang terjadi pada dirinya.

Pubertas dipengaruhi oleh beberapa sinyal termasuk neurotransmiter dan neuropeptida yang berasal dari hipotalamus yang diteruskan ke perifer dan gonad. Variasi usia pubertas melibatkan $74 \%$ faktor genetik dan $26 \%$ faktor lingkungan. Faktor lingkungan meliputi letak geografis, status sosial ekonomi, infeksi, iklim, stresor, dan gangguan pada sistem endokrin yang mempengaruhi jaringan sinyal hipotalamus ${ }^{(2)}$

Orang tua merupakan guru utama untuk anak-anaknya, maka dari itu orang tua merupakan pusat sentral yang dijadikan sorotan dalam perkembangan anak, baik perkembangan fisik maupun psikis ${ }^{(3)}$. Pola asuh orang tua merupakan kemampuan orang tua untuk menyediakan waktu, perhatian, dan dukungan terhadap anak agar dapat tumbuh dan berkembang 
dengan sebaik-baiknya ${ }^{(4)}$. Pola asuh orang tua merupakan perilaku dan sikap orang tua, memiliki efek yang langsung terhadap perkembangan dan kesejahteraan anakanak mereka. Ini meliputi keluarga (lingkungan terdekat), dan menyentuh setiap aspek kehidupan setiap anak ${ }^{(5)}$.

Berdasarkan latar belakang di atas dan studi pendahuluan yang dilakukan peneliti pada tanggal 25 November 2015 terhadap 10 siswa didapatkan hasil dari 10 siswa sudah menunjukan pola perkembangan seksual sekunder yaitu 4 siswa telah berjerawat dan 6 siswa sudah tumbuh kumis.

\section{BAHAN DAN CARA PENELITIAN}

Penelitian ini merupakan jenis penelitian Observational analitik dengan menggunakan desain penelitian cross sectional. Populasi penelitian ini adalah semua siswa laki-laki SMP Negeri 1 Berbah Yogyakarta sebanyak 188 siswa. Pengambilan sampel dengan cara purposive sampling. Pengambilan sampling dilakukan dengan menetapkan kriteria inklusi dengan jumlah 143 responden. Variabel bebas (independen) dalam penelitian ini adalah pola asuh, variabel terikat (dependen) adalah pola perkembangan seksual sekunder dan variabel penggangu adalah faktor lingkungan dan sosial ekonomi. Intrumen penelitian yang digunakan adalah berupa kuesioner untuk mengetahui jenis poa asuh orang tua dan pola perkembangan seksual sekunder. Metode analisis data menggunakan tabulasi silang/chi square.

\section{HASIL DAN PEMBAHASAN}

Karakteristik responden berdasarkan umur, pendidikan orangtua, dan tinggal bersama dapat dilihat pada tabel 1 berikut:

Tabel 1. Distribusi Frekuensi Berdasarkan Umur, Pendidikan Orang Tua,

\begin{tabular}{|c|c|c|}
\hline Karakteristik & Frequency & Percent \\
\hline \multicolumn{3}{|l|}{ Umur Respunden } \\
\hline 13 tahun & 43 & 30 \\
\hline 14 tahun & 59 & 41.3 \\
\hline 15 tahun & 41 & 28.7 \\
\hline \multicolumn{3}{|c|}{ Pendidikan Orang Tua } \\
\hline SD & 6 & 4.2 \\
\hline SMP & 30 & 21 \\
\hline SMA/SMK & 71 & 49.6 \\
\hline Perguruan Tinggi & 36 & 25.2 \\
\hline \multicolumn{3}{|l|}{ Tinggal Bersama } \\
\hline Kedua Orangtua & 135 & 94.4 \\
\hline Orangtua tunggal & 3 & 2.1 \\
\hline Paman/Bibi & 3 & 2.1 \\
\hline Saudara & 2 & 1.4 \\
\hline
\end{tabular}
karakteristik responden dalam penelitian ini berdasarkan kategori usia didominasi oleh responden yang berumur 14 tahun sebanyak 59 (41,3\%), kategori tingkat pendidikan orangtua didominasi oleh orangtua responden yang berpendidikan SMA sebanyak 71 orang $(49,6 \%)$, kategori tinggal bersama didominasi oleh tinggal bersama kedua orang tua responden sebanyak 135 orang (94,4\%).

Tabel 2. Distribusi Pola Asuh dan Pola PerkembanganSeksual Sekunder.

\begin{tabular}{lcc}
\hline \multicolumn{1}{c}{ Variabel } & Jumlah & Persentase \\
\hline Pola Asuh & & \\
Otoriter & 42 & 30.07 \\
Permisif & 39 & 27.27 \\
Demokratis & 62 & 42.66 \\
\hline Pola perkembangan & & \\
seksual sekunder & & \\
Belum mengalami & 30 & 29 \\
\hline
\end{tabular}




\begin{tabular}{lcc}
\hline mengalami & 113 & 71 \\
\hline Jumlah & 143 & 100 \\
\hline
\end{tabular}

Berdasarkan Tabel 2, dapat diketahui bahwa dalam penelitian pola asuh yang diterapkan oleh orang tua siswa didominasi pola asuh demokratis sebanyak 62 responden $(42,66 \%)$, dan kriteria pola perkembangan seksual sekunder siswa yang mengalami pola perkembangan seksual sekunder sebanyak 113 responden (71\%).

Analisis bivariat tahap ini diteliti "Hubungan Pola Asuh dengan Pola Perkembangan Seksual Sekunder Siswa SMP Negeri I Berbah Yogyakarta” dengan menggunakan uji chi Square, dapat diketahui sebagai berikut :

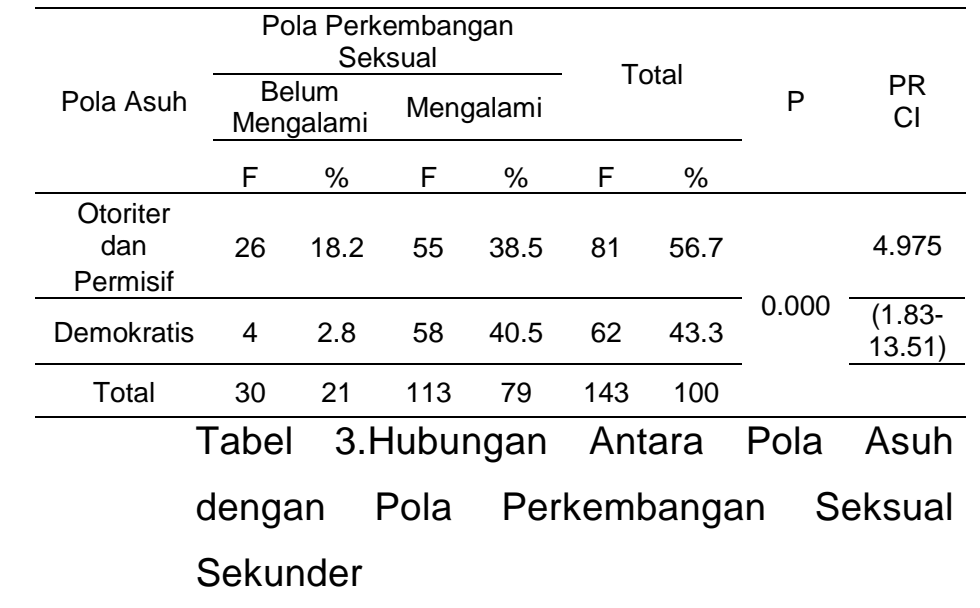

Berdasarkan tabel 3 diketahui bahwa pola asuh otoriter dan permisif diterapkan oleh 81 orangtua (56,7\%), dalam penerapan pola asuh otoriter dan pola asuh permisif siswa yang belum mengalami pola perkembangan sebanyak 26 responden (18,2\%). Sedangkan pola asuh demokratis diterapkan oleh 62 orangtua $(43,3 \%)$, dalam penerapan pola asuh demokratis mengalami pola perkembangan seksual sekunder sebanyak 58 responden (40,5\%). Hasil pengujian Chisquare diperoleh nilai Exact Sig (2-sided) sebesar $0,000<0,05$ sehingga dapat disimpulkan bahwa terdapat hubungan antara pola asuh terhadap pola perkembangan seksual sekunder yang dialami siswa sekolah di SMP Negeri 1 Berbah. Sedangkan parameter kekuatan hubungan yaitu nilai PR (Prevalence Rate) sebesar 4,975 artinya responden dengan model pola asuh otoriter dan permisif berisiko 4,975 kali belum mengalami perkembangan seksual sekunder dibandingkan dengan responden dengan pola asuh demokratis. Nilai $\mathrm{Cl}$ (Confident Interval) $95 \%$ sebesar 1,831-13,516 bila rasio prevalensi $>1$, dan interval kepercayaan tidak mencangkup angka 1, maka dapat disimpulkan variabel pola asuh merupakan faktor risiko terhadap pola perkembangan seksual sekunder.

\section{PEMBAHASAN}

Berdasarkan temuan yang diperoleh dari lapangan, karateristik responden dalam penilitian ini berdasarkan umur didominasi oleh umur 14 tahun sebanyak 59 orang $(41,3 \%)$ didapatkan pada siswa kelas VIII dan paling sedikit umur 15 tahun sebanyak 41 orang $(28,7 \%)$ pada siswa kelas IX. Temuan selanjutnya terkait pola asuh orang tua, siswa dengan pola asuh demokratis sebanyak 62 siswa (42,66\%) dan yang paling rendah yaitu pola asuh permisif 
sebanyak 39 siswa $(27,27 \%)$. Pola perkembangan seksual sekunder didominasi oleh siswa yang telah mengalami pola perkembangan seksual sekunder sebanyak 113 siswa (79\%) dan siswa yang belum mengalami sebanyak 30 siswa (21\%).

Hasil bivariat diperoleh nilai signifikansi $0,000<0,05$ artinya Ada Hubungan Antara. Pola Asuh dengan Pola Seksual Sekunder Siswa SMP Negeri 1 Berbah Yogyakarta. Nilai PR (Prevalence Rate) sebesar 4,975 artinya responden dengan model pola asuh otoriter dan permisif berisiko 4,975 kali belum mengalami perkembangan seksual sekunder dibandingkan dengan responden dengan pola asuh demokratis. Nilai $\mathrm{Cl}$ (Confident Interval) 95\% sebesar 1,83113,516 bila rasio prevalensi $>1$, dan interval kepercayaan tidak mencangkup angka 1, maka dapat disimpulkan variabel pola asuh merupakan faktor risiko terhadap pola perkembangan seksual sekunder. Program sosialisasi dan bimbingan remaja yang belum dibentuk disekolah kepada siswa membuat siswa kurang mendapatkan pengetahuan tentang perubahan fisik yang dialami selama pubertas. Program bimbingan remaja seperti PIK-R yang belum terbentuk di sekolah membuat siswa kurang mendapatkan bimbingan dan informasi tambahan mengenai perubahan fisik selama remaja.
Penelitian lain menyebutkan bahwa adanya hubungan antara konflik keluarga, faktor genetik, dan lingkungan terhadap perkembangan pubertas. Penelitian ini dilakukan pada anak remaja berusia antara 12-16 tahun, sebesar 2081 terdiri dari 1036 anak laki-laki dan 1045 anak perempuan di sekolah negeri di daerah perkotaan yang terletak di sebelah timur kota Madrid. Hasil menunjukan bahwa faktor konflik keluarga dan usia lebih berpengaruh terhadap perkembangan pubertas ${ }^{(6)}$.

Hasil yang diperoleh sesuai dengan penelitian bahwa ada hubungan antara pengetahuan dan sikap remaja mengenai perubahan fisik dan psikososial pada masa pubertas pada siswa putra dan putri SMP Taruna Bakti Depok. Hasil penelitian tersebut menunjukan dari 42 responden $(43,7 \%)$ siswa laki-laki telah mengalami tanda perkembangan pubertas yaitu emisi nocturnal (mimpi basah). Aspek psikososial yang meliputi peran keluarga mampu memberikan pengaruh terhadap perkembangan pubertas remaja ${ }^{(7)}$.

Terkait dengan perkembangan seksual sekunder hasil serupa juga diperoleh bahwa ada hubungan antara faktor lingkungan yang meliputi lingkungan keluarga, teman dan nutrisi dan kesehatan terhadap perkembangan pubertas pada remaja lakilaki Amerika berkulit hitam dan putih. Hasil penelitian menunjukan 364 remaja laki-laki kulit putih dan 63 remaja laki-laki kulit hitam telah menunjukan perkembangan 
seksual sekunder dengan tingkat perkembangan muturitas kelamin (TMK) pada skala 3 dan $4^{\left({ }^{(8)}\right.}$. TMK 3 adalah responden laki-laki memiliki rambut pubis yang lebih gelap, rambut mulai keriting, jumlah sedikit dan menyebar ke mens pubis memiliki penis yang lebih panjang, dan volume testis yang lebih besar. TMK 4 artinya responden laki-laki memiliki tipe dan distribusi rambut pubis seperti dewasa, kasar, keriting, dan jumlah lebih sedikit, memiliki testis lebih besar dan glans penis membesar, dan volume testis lebih besar, skrotum menghitam ${ }^{(9)}$.

Urutan timbulnya ciri seksual sekunder diawali oleh perubahan suara, diikuti perubahan kulit menjadi lebih kasar, otot menjadi lebih besar atau berisi, mulai tumbuhnya kumis di wajah, dan timbulnya jerawat. Selama pertumbuhan pesat masa puber terjadi, terdapat empat perubahan fisik penting di mana tubuh yaitu perubahan ukuran tubuh, perubahan proporsi tubuh perkembangan ciri-ciri seksual primer dan sekunder perubahan ciri-ciri seksual sekunder meliputi perubahan rambut, kulit, kelenjar, otot, benjolan dada, dan suara ${ }^{(10)}$.

Beberapa fakta temuan di lapangan menunjukan masih banyak siswa yang kurang begitu memahami tentang perubahan pubertas, siswa belum mengerti tentang perubahan seksual sekunder dan tanda-tanda yang muncul, mereka menganggap perubahan yang terjadi pada diri mereka merupakan suatu hal yang wajar. Sampai abad ini penyebab perubahan fisik yang terjadi pada masa puber masih merupakan misteri. Dengan banyaknya riset di bidang endrokrinologi, ilmu medis telah mampu menetapkan sebab yang pasti dari perubahan fisik, meskipun sampai sekarang para ahli endrolinologi tidak dapat menerangkan adanya keanerakagaman dalam usia puber dan dalam waktu yang diperlukan untuk menyelesaikan perubahan pubertas. Hubungan yang erat antara kelanjar pituitary yang terletak pada dasar otak telah terbentuk bersama dengan gonad atau kelenjar seksual ${ }^{(11)}$.

Berdasarkan hasil penelitian yang telah dilakukan dan pengolahan data hasil dari kuesioner dapat disimpulkan sebagian besar responden dalam penelitian ini telah mengalami perkembangan seksual sekunder. Berdasarkan penelitian ini dapat dilihat bahwa model pola asuh orang tua mampu mempengaruhi tumbuh kembang anak, model pola asuh yang diberikan oleh orang tua mampu mempengaruhi keadaan emosional seperti gangguan psikologis sehingga mempengaruhi perkembangan fisik remaja.

Faktor-faktor yang mempengaruhi perkembangan remaja antara lain pengaruh keluarga, pengaruh gizi, gangguan emosional, jenis kelamin, status sosial ekonomi, kesehatan dan pengaruh bentuk tubuh. Di samping itu pengaruh lingkungan letak geografis, infeksi, iklim, stresor, dan 
gangguan pada sistem endokrin yang mempengaruhi jaringan sinyal hipotalamus dan status sosial ekonomi mempengaruhi perkembangan fisik remaja. Sosialisasi tentang kesehatan reproduksi dan remaja yang dilaksanakan di sekolah merupakan kerjasama dengan Puskesmas setempat, kegiatan tersebut dilaksanakan 3 bulan sekali. Belum adanya bimbingan di sekolah kepada siswa tentang kesehatan reproduksi dan remaja seperti PIK R (Pusat Informasi dan konseling Remaja) ${ }^{(12)}$.

\section{SIMPULAN DAN SARAN}

Kesimpulannya yaitu ada hubungan antara pola Asuh dengan Pola Perkembangan Seksual Sekunder Siswa di SMP Negeri 1 Berbah Yogyakarta. Saran kepada Institusi Sekolah hendaknya membentuk PIKR (Pusat Informasi Konseling Remaja) sebagai wadah pelayanan informasi dan konseling kesehatan reproduksi remaja. Bagi peneliti selanjutnya untuk dapat melakukan penelitian mengenai seksual sekunder dengan mengambil variabel lain selain pola asuh seperti faktor lingkungan dan faktor sosial ekonomi.

\section{KEPUSTAKAAN}

1. Suryani, L., Syahniar., Zikra, Penyeseuaian Diri Pada Masa Pubertas, Jurnal IImiah Konseling, 2013. Vol 2 (1), UNP.

2. Batubara, J.RL, Adolescent Development (Perkembangan Remaja). Departemen
IImu Kesehatan Anak, RS Dr. Cipto Mangunkusumo, Jurnal Kedokteran Fakultas Kedokteran Universitas Indonesia, Jakarta. 2010.

3. Depkes R.I, Orang Tua dan Remaja, 2006, http:/www.DepkesRI.go.id/litbang, diakses pada tanggal 15 Mei 2015 jam 22.30, Yogyakarta.

4. Sapril, R.A., Jamaluddin, M., Nurbaya, St, Hubungan Antara Pola Asuh Orang Tua dengan Perkembangan Anak Usia 35 Tahun di TK Islam Qalbin Salim Makassar, Jurnal Keperawatan, 2013, Vol 3 (3), Stikes Nani Hasanuddin Makassar.

5. Israfil, Hubungan Pola Asuh Orang Tua dengan Perkembangan Anak Usia Prasekolah, Jurnal Psikologi. 2015, Vol 5 (2), Universitas Muhamadiyah Malang.

6. Moralez, D.J.F., Escribano, C., Jankowski, K.S, Vollmer, C., Randler, C, Evening Adolescent: The Role of Family Relationship and Pubertal Development, Journal of Adolescence, 2014,. Vol: 37 (425-432), University of Madrid, Spain.

7. Jihadi, A., Suparman, A, hubungan antara pengetahuan dan sikap remaja mengenai perubahan fisik dan psikososial pada masa pubertas pada siswa putra dan putri SMP Taruna Bakti Depok, Jurnal Kedokteran Fakultas Kedokteran Universitas Indonesia. 2013.

8. Susman, E., Houth, Longitudinal Development of Secondary Sexual Characteristics in Girls and Boys 
Between Ages $91 / 2$ and 151/2 Year

Tanner, e-Book, New York McMillan Publ

Co, New York. 2011.

9. Soetjiningsih, Tumbuh Kembang Anak,

EGC Edisi 2, Jakarta. 2014,

10. Hurlock, E.B, Psikologi Perkembangan,

Suatu Pendekatan Sepanjang Rentang

Kehidupan, Erlangga Edisi: 5 (1).

Jakarta. 2009.

11. Santrock, J.W, Remaja, Erlangga Edisi:

11 (1). Jakarta. 2007.

12. Dewi, H.E, Memahami Perkembangan

Fisik Remaja, Gosyen Publishing, Jilid

1, Jakarta. 2012. 